\title{
EFFECT OF ACTIVITY PARTICLE SIZE DISTRIBUTION ON DEPOSITION FRACTION OF INHALED RADON DECAY PRODUCTS IN HUMAN RESPIRATORY SYSTEM
}

\author{
Sara Sakr ${ }^{1}, \underline{\text { M. Y.A. Mostafa }}{ }^{1,2^{*}}$, A. Mohamed ${ }^{1}$, A.A. Ahmed ${ }^{1}$, Mona moustafa ${ }^{1}$ \\ 1) Department of Physics, Minia University, El-Minia, Egypt \\ ${ }^{2)}$ Ural Federal University, Yekaterinburg, Russia \\ *E-mail: Mostafa 85@mail.ru
}

The activity particle size distribution is an important factor governing if the aerosols can be deposited at various respiratory tract regions in human. Radon decay products are the second cause of lung cancer after smoking. A lot of dosimetric models have been built in to calculate the effective dose and effective depth dose in different region and tissues of human respiratory system ${ }^{1}$. The deposition fraction estimation is the first step of dose calculation. Therefore, the dependence of radioactive aerosols deposition fraction in human respiratory system on their size should be studied. In this work, the activity size distributions of ${ }^{222} \mathrm{Rn}$ decay products $\left({ }^{218} \mathrm{Po},{ }^{214} \mathrm{~Pb}\right.$ and ${ }^{214} \mathrm{Bi}$, ) are measured in indoor air. Only unattached fraction of ${ }^{218} \mathrm{Po}$ (active median thermodynamic diameter AMTD 1-1.5 nm) was measured with developed diffusion battery. Nearly $85 \%$ of ${ }^{218} \mathrm{Po}$ activity is free with its short half-life time. Most of the measured attached activities of $\left({ }^{214} \mathrm{~Pb}\right.$ and $\left.{ }^{214} \mathrm{Bi}\right)$ are associated with the aerosol particles of the accumulation mode $(0.2 \mu \mathrm{m}$ to $2 \mu \mathrm{m})$. The activity distribution of the two radionuclides is typically identical. The active median aerodynamic diameter (AMAD) is $0.42 \mu \mathrm{m}$ with a geometric standard deviation (GSD) of 3.4. Given that dose estimation is sensitive to environmental conditions and based on the obtained experimental results, the local energy deposition of $\left({ }^{214} \mathrm{~Pb}\right.$ and $\left.{ }^{214} \mathrm{Bi}\right)$ by adult male for various levels of physical exertion (sleeping, sitting, light exercise and Heavy exercise) is computed with LUDEP program. For unattached particles $(1-5 \mathrm{~nm})$ nearly $98 \%$ are deposited unlike accumulated fraction $(0.42 \mu \mathrm{m}$ in our case) not more $30 \%$ is deposited in the respiratory system.
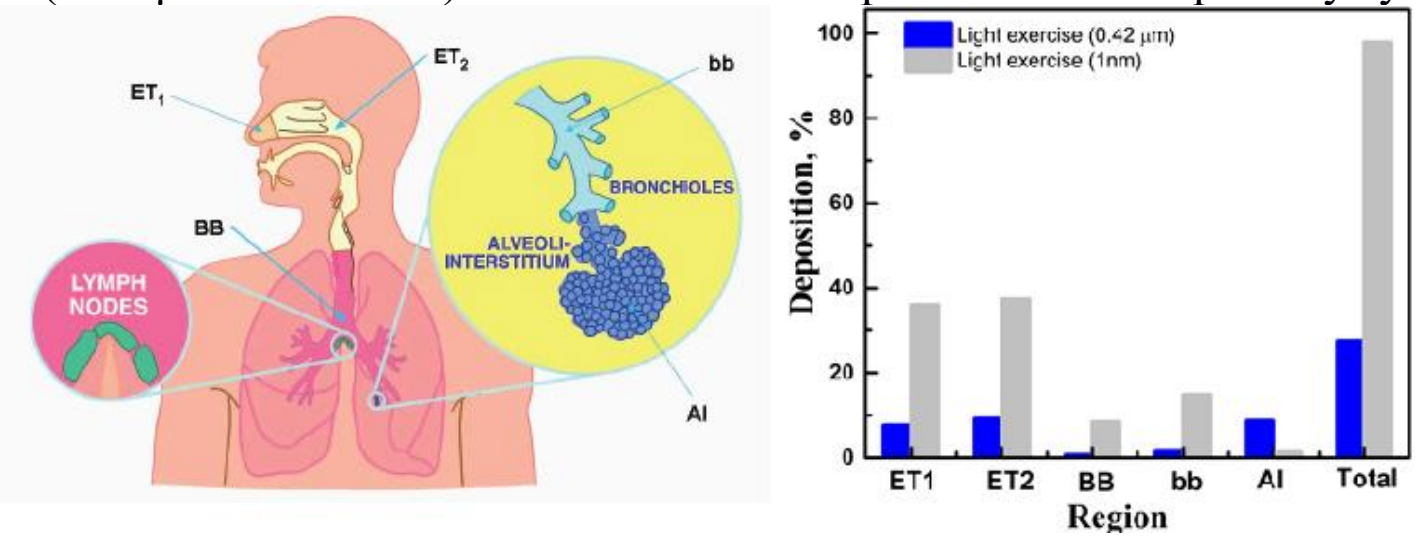

Fig. 1. Deposition fractions of attached $(0.42 \mu \mathrm{m})$ and unattached $(1 \mathrm{~nm})$ radon progeny in different regions of human respiratory tract for physical exertion light exercise.

3. Yuness M, Mohamed A, AbdEl-hady M, et al. Appl Radiat Isot., 97, 34-39 (2015) 